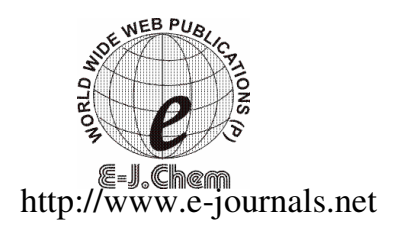

\title{
Synthesis, Characterisation, Spectral and Microbial Studies of Transition Metal Complexes of the Drug, Secnidazole
}

\author{
ARADHANA VERMA*, S. A. IQBAL, ARUN SINGH and LIVIU MITU \\ Department of Chemistry, Govt. Geetanjali Girls' PG College Bhopal, India \\ Department of Chemistry, Safia Science College, Bhopal-462001, India \\ Joint Director Rajaya Siksha Kendra, Bhopal, India \\ Department of Physics and Chemistry \\ University of Pitesti, Pitesti - 110 040, Romania \\ iqbalospc@yahoo.com
}

Received 20 February 2010; Accepted 1 May 2010

\begin{abstract}
Chloromethyl-8-quinolinol hydrochloride was condensed with 1-(2-methyl-5-nitro-1H-imidazol-1-yl)propan-2-ol in presence of potassium carbonate. The resulting 5-((1-(2-methyl-5-nitro-1H-imidazol-1-yl)propan-2yloxy)methyl)quinolin-8-ol was characterized by elemental analysis and spectral studies. The transition metal chelates of the same were prepared with $\mathrm{Cu}^{2+}, \mathrm{Ni}^{2+}, \mathrm{Co}^{2+}, \mathrm{Mn}^{2+}$ and $\mathrm{Zn}^{2+}$ and characterized by IR and electronic spectral studies and magnetic properties. The antimicrobial activity of ligand and its metal chelates were screened against various gram positive and gram negative organisms. The results show that all these samples are more or less active agents against various organisms.
\end{abstract}

Keywords: 1-(2-Methyl-5-nitro-1H-imidazol-1-yl)propan-2-ol, Antimicrobial activity, Metal chelates.

\section{Introduction}

In continuation of our work of synthesis and characterization of metal complexes of established drugs ${ }^{1-14}$, here we report the synthesis and studies of secnidazole metal complexes.

8-Hydroxyquinoline or 8 -quinolinol is well known as an analytical reagent ${ }^{15,16}$. Its various derivatives ${ }^{17}$ are also useful in pharmaceuticals more particularly antiprotozoal drug. One of the derivative say, 5-chloromethyl 8-quinolinol (CMQ) can be synthesize easily and studied for number of useful compounds and polymers ${ }^{18-28}$. One of the heterocyclic drug say compound based on secnidazole is well known as an important antiamoibic drug. 
If we carried out the formation of secnidazole-CMQ merged molecule and it's heterochelate, then such molecules may have antimicrobial activity up to good extent. Hence it was thought to study the heterochelate of compound based on secnidazole and CMQ. Thus the present paper comprises the synthesis, characterization, chelating properties and antimicrobial activity of 5-((1-(2-methyl-5-nitro- $1 H$-imidazol-1-yl)propan-2-yloxy) methyl) quinolin-8-ol molecule (1- $(H)$-secnidazole- CMQ merged molecule). The reaction route is shown in Scheme 1.<smiles></smiles>

5-(Chloromethyl)quinolin-8-ol-hydrochloride<smiles>Cc1ncc([N+](=O)[O-])n1CC(C)O</smiles>

1-(2-Methyl-5-nitro-1H-imidazole-1-yl)propan-2-ol (i.e. 1-(H)-Secnidazole)<smiles></smiles>

[where $\mathrm{M}: \mathrm{Cu}^{2+}, \mathrm{Ni}^{2+}, \mathrm{Co}^{2+}, \mathrm{Zn}^{2+}, \mathrm{Mn}^{2+}$ ]

Scheme 1. Proposed structure of heterochelate

\section{Experimental}

5-Chloromethyl-8-quinolinol (CMQ) hydrochloride was prepared according to method reported in literature ${ }^{18}$. Compound based on secnidazole was obtained from local dealer. All other chemicals used were of laboratory grade of purity. 
Synthesis of 5-((1-(2-methyl-5-nitro-1H-imidazol-1-yl) propan-2-yloxy) methyl) quinolin-8-ol (Formation of MIPQ)

In a round bottom flask, to a suspension of 5-chloromethyl-8-quinolinol (CMQ) hydrochloride $(23 \mathrm{~g}, 0.1 \mathrm{~mol})$ in dry acetone $(100 \mathrm{~mL}), 1-(H)$-Secnidazole $(0.1 \mathrm{~mol})$ was added gradually at room temperature. Potassium carbonate $(16.8 \mathrm{~g})$ was added in the mixture and the mixture was refluxed on water bath for $8 \mathrm{~h}$. The resulting solid mass was added in to water and the precipitation was filtered off, washed with boiling water and the air dried. It was dark green amorphous powder. It was insoluble in common organic solvent but soluble only in formic acid and DMSO.

Analysis

The prepared ligand was analyzed for elemental analysis, ${ }^{1} \mathrm{H}$ NMR and IR spectral studies which results are as shown below;

\section{Elemental analysis}

$\mathrm{C}_{17} \mathrm{H}_{18} \mathrm{~N}_{4} \mathrm{O}_{4}$ (M.W. 342.35)

$\begin{array}{lcccc} & & \mathrm{C} \% & \mathrm{H} \% & \mathrm{~N} \% \\ \text { Calculated } & : & 59.64 & 5.30 & 16.37 \\ \text { Found } & : & 59.55 & 5.13 & 16.20\end{array}$

Spectral data

IR $\left(\mathrm{cm}^{-1}\right)$ : (2980, 2850, $1470\left(-\mathrm{CH}_{2}\right), 1630,1575,1500(8 \mathrm{HQ}) 1700$ (-CO-), 1680 (carbamide).

NMR $\left(\delta\right.$ ppm): 7.07-8.86 (6H, Ar-H), $5.35(1 \mathrm{H},-\mathrm{OH}), 4.63\left(2 \mathrm{H},-\mathrm{CH}_{2}\right), 3.9-3.7\left(2 \mathrm{H},-\mathrm{CH}_{2}\right)$, $2.5\left(3 \mathrm{H}\right.$, Aromatic $\left.\mathrm{CH}_{3}\right), 1.1$ (Aliphatic $\left.\mathrm{CH}_{3}\right)$.

Synthesis of $M I P Q$

MIPQ (0.05 mol) was taken in $500 \mathrm{~mL}$ beaker. Formic acid was added up to slurry formation. To this slurry water was added till the complete dissolution of MIPQ. It was diluted to $100 \mathrm{~mL}$.

In a solution of metal acetate $(0.005 \mathrm{~mol})$ in acetone: water $(50: 50 \mathrm{v} / \mathrm{v})$ mixture $(40 \mathrm{~mL})$ $20 \mathrm{~mL}$ of above mentioned MIPQ solution (i.e. containing $0.01 \mathrm{M}$ Secnidazole) was added with vigorous stirring at room temperature. The appropriate $\mathrm{pH}$ was adjusted by addition of sodium acetate for complete precipitation of metal chelate. The precipitates were digested on a boiling water bath. The precipitates of chelate were filtered off, washed by water and air dried.

\section{Measurements}

The elemental contents of $\mathrm{C}, \mathrm{H}, \mathrm{N}$ were determined by TF-Flash-1101 EA, The metals contents of metal chelates were determined volumetrically by Vogel's method ${ }^{29 .}$ To a $100 \mathrm{mg}$ chelate sample, each $1 \mathrm{~mL}$ of $\mathrm{HCl}, \mathrm{H}_{2} \mathrm{SO}_{4}$ and $\mathrm{HClO}_{4}$ were added and then $1 \mathrm{~g}$ of $\mathrm{NaClO}_{4}$ was added. The mixture was evaporated to dryness and the resulting salt was dissolved in double distilled water and diluted to the mark. From this solution the metal content was determined by titration with standard EDTA solution. Infrared spectra of the synthesized compounds were recorded on Nicolet 760 FT-IR spectrometers. NMR spectrum of secnidazole was recorded on $400 \mathrm{MHz}$ NMR spectrophotometer. Magnetic susceptibility measurement of the synthesized complexes was carried out on Gouy balance at room temperature. The electronic spectra of complexes in solid were recorded at room temperature. $\mathrm{MgO}$ was used as reference. Antimicrobial activity of all the samples was monitored against various gram positive and gram negative organism, following the method reported in the literature $\mathrm{r}^{30,31}$. 


\section{Results and Discussion}

The synthesis of 5-((1-(2-methyl-5-nitro-1H-imidazol-1-yl)propan-2-yloxy)methyl)quinolin-8ol was performed by a simple nucleophilic substitution reaction of 1-(2-methyl-5-nitro- $1 \mathrm{H}$ imidazol-1-yl)propan-2-ol and 5-chloromethyl-8-quinolinol hydrochloride (CMQ). The resulted 1- $(H)$-secnidazole ligand was an amorphous color powder. The ligand is characterized by elemental analysis as well as ${ }^{1} \mathrm{H}$ NMR and IR spectroscopic techniques as given below.

Elemental analysis

The obtained $\mathrm{C}, \mathrm{H}, \mathrm{N}$ contents of 1- $(H)$-Secnidazole and its heterochelates are in good agreement with the calculated one as shown in Table 1.

Table 1. Analysis of MIPQ ligand and its heterochelates

\begin{tabular}{|c|c|c|c|c|c|c|c|c|c|c|}
\hline \multirow{3}{*}{ Empirical Formula } & \multirow{3}{*}{$\begin{array}{l}\sum_{0} \frac{0}{0} \\
\dot{\Sigma}\end{array}$} & \multirow{3}{*}{$\begin{array}{l}00 \\
\frac{0}{0} \\
i\end{array}$} & \multicolumn{8}{|c|}{ Elemental Analysis, \% } \\
\hline & & & \multicolumn{2}{|r|}{$\mathrm{C}$} & \multicolumn{2}{|r|}{$\mathrm{H}$} & \multicolumn{2}{|r|}{$\mathrm{N}$} & \multicolumn{2}{|r|}{$M$} \\
\hline & & & Cal. & Found & Cal & Found & Cal & Found & $\mathrm{Cal}$ & Found \\
\hline $\mathrm{C}_{17} \mathrm{H}_{18} \mathrm{~N}_{4} \mathrm{O}_{4}$ & 342 & 92 & 59.64 & 59.22 & 5.30 & 5.11 & 5.30 & 5.25 & - & - \\
\hline $\mathrm{C}_{34} \mathrm{H}_{34} \mathrm{~N}_{8} \mathrm{O}_{8} \mathrm{Cu}^{2+} \cdot \mathrm{H}_{2} \mathrm{O}$ & 764 & 78 & 53.43 & 53.13 & 4.75 & 4.44 & 14.66 & 14.15 & 8.31 & 8.11 \\
\hline $\mathrm{C}_{34} \mathrm{H}_{34} \mathrm{~N}_{8} \mathrm{O}_{8} \mathrm{Ni}^{2+} \cdot \mathrm{H}_{2} \mathrm{O}$ & 759 & 83 & 53.78 & 53.40 & 4.78 & 4.67 & 14.76 & 14.34 & 7.73 & 7.57 \\
\hline $\mathrm{C}_{34} \mathrm{H}_{34} \mathrm{~N}_{8} \mathrm{O}_{8} \mathrm{Co}^{2+} . \mathrm{H}_{2} \mathrm{O}$ & 759 & 85 & 53.76 & 53.63 & 4.78 & 4.75 & 14.75 & 14.10 & 7.76 & 7.70 \\
\hline $\mathrm{C}_{34} \mathrm{H}_{34} \mathrm{~N}_{8} \mathrm{O}_{8} \mathrm{Mn}^{2+} \cdot \mathrm{H}_{2} \mathrm{O}$ & 755 & 82 & 54.04 & 54.24 & 4.80 & 4.71 & 14.83 & 14.36 & 7.27 & 7.26 \\
\hline $\mathrm{C}_{34} \mathrm{H}_{34} \mathrm{~N}_{8} \mathrm{O}_{8} \mathrm{Zn}^{2+} . \mathrm{H}_{2} \mathrm{O}$ & 766 & 77 & 53.30 & 53.26 & 4.74 & 4.65 & 14.63 & 14.39 & 8.54 & 8.51 \\
\hline
\end{tabular}

IR analysis

The important infrared spectral bands and their tentative assignments for the synthesized ligands $1-(H)$-secnidazole and its complexes were recorded as $\mathrm{KBr}$ disks and the data of complexes and ligand are presented in Table 2.

The IR spectrum of comprises the important bands due to 8-quinolinol. The bands were observed at 1635, 1575, 1472 and $755 \mathrm{~cm}^{-1}$. The broad band in ligand and all the complexes at $3800-2700 \mathrm{~cm}^{-1}$ is due to the presence of $-\mathrm{OH}$ group. The band at $1700 \mathrm{~cm}^{-1}$ is due to CO- group. The band at $1670 \mathrm{~cm}^{-1}$ might be due to carbamide group. In this band the inflections are observed at 2950, 2920 and $2850 \mathrm{~cm}^{-1}$. While the latter two might be attributed to asymmetric and symmetric vibration of $-\mathrm{CH}_{2}$ group of CMQ.

The infrared spectra of all the complexes are identical and suggest the formation of the entire metalocyclic compound by the absence of band characteristic of free $-\mathrm{OH}$ group of parent 1-(H)-secnidazole. The other bands are almost at their respectable positions as appeared in the spectrum of parent 1- $(H)$-secnidazole ligand.

However, in the far-IR region, two new bands in the range of 444-472 and 410-430 $\mathrm{cm}^{-1}$ in the all the complexes are assigned the binding of metal with oxygen and nitrogen atom of CMQ respectively.

\section{${ }^{1} H$ NMR analysis}

The ${ }^{1} \mathrm{H}$ NMR spectrum of $1-(H)$-secnidazole is carried out in DMSO-d ${ }^{6}$ using as solvent indicates that singlet at $1.1 \delta \mathrm{ppm}$ due to the aliphatic $-\mathrm{CH}_{3}$ group protons, where the singlet at $2.5 \delta \mathrm{ppm}$ due to the aromatic $-\mathrm{CH}_{3}$ group protons, two peaks at 3.7-3.9 and $4.6 \delta \mathrm{ppm}$ indicate the two doublets of $-\mathrm{CH}_{2}$ group protons, where the broad peak at $5.35 \delta \mathrm{ppm}$ indicate the $-\mathrm{OH}$ group proton, the range of 7.07-8.86 $\delta \mathrm{ppm}$ indicate the 6 protons for the aromatic region. The vigorous oxidation of 1-(H)-secnidazole yielded 8-hydroxy quinoline-5-carboxylic acid ${ }^{27}$ (m.p. $\left.230{ }^{\circ} \mathrm{C}\right)$. Thus the structure of $1-(H)$-secnidazole is confirmed as shown in Scheme 1. 


\section{Magnetic measurements}

Magnetic moments of heterochelates are given in Table 2. The diffuse electronic spectrum of $\mathrm{Cu}^{2+}$ chelates shows two broad bands around 13000 and $23000 \mathrm{~cm}^{-1}$. The first band may be due to a ${ }^{2} \mathrm{~B}_{1 \mathrm{~g}} \rightarrow{ }^{1} \mathrm{~A}_{1 \mathrm{~g}}$ transition, while the second band may be due to charge transfer. The first band shows structures suggesting a distorted octahedral structure for the $\mathrm{Cu}^{2+}$ metal chelates ${ }^{32,33}$. The higher value of the magnetic moment of the $\mathrm{Cu}^{2+}$ chelate supports the same. The $\mathrm{Co}^{2+}$ metal chelate gives rise to two absorption bands at 23800 and $19040 \mathrm{~cm}^{-1}$, which can be assigned ${ }^{4} \mathrm{~T}_{1 \mathrm{~g}} \rightarrow{ }^{2} \mathrm{~T}_{2 \mathrm{~g}},{ }^{4} \mathrm{~T}_{1 \mathrm{~g}} \rightarrow{ }^{4} \mathrm{~T}_{1 \mathrm{~g}}(\mathrm{P})$ transitions, respectively. These absorption bands and the $\mu_{\text {eff }}$ value indicate an octahedral configuration of the $\mathrm{Co}^{2+}$ metal chelate ${ }^{34,35}$. The spectrum of $\mathrm{Mn}^{2+}$ polymeric chelate comprised two bands at $19019 \mathrm{~cm}^{-1}$ and $23301 \mathrm{~cm}^{-1}$. The latter does not have a very long tail. These bands may be assigned to ${ }^{6} \mathrm{~A}_{1 \mathrm{~g}} \rightarrow{ }^{4} \mathrm{~T}_{2 \mathrm{~g}}(\mathrm{G})$ and ${ }^{6} \mathrm{~A}_{1 \mathrm{~g}} \rightarrow{ }^{4} \mathrm{~A}_{2 \mathrm{~g}}(\mathrm{G})$ transitions, respectively. The high intensity of the bands suggests that they may have some charge transfer character. The magnetic moment is found to be lower than normal range. In the absence of low temperature measurement of magnetic moment it is difficult to attach any significance to this. As the spectrum of the metal chelate of $\mathrm{Ni}^{2+}$ show two Sistine bands at 11961-11490 and 17701-17400 $\mathrm{cm}^{-1}$ are assigned as ${ }^{3} \mathrm{~A}_{2 \mathrm{~g}}(\mathrm{~F}) \rightarrow{ }^{3} \mathrm{~T}_{1 \mathrm{~g}}(\mathrm{~F})$ and ${ }^{3} \mathrm{~A}_{2 \mathrm{~g}}(\mathrm{~F}) \rightarrow{ }^{3} \mathrm{~T}_{1 \mathrm{~g}}(\mathrm{~F})$ transition, respectively suggested the octahedral environment for $\mathrm{Ni}^{2+}$ ion. The observed $\mu_{\text {eff }}$ values in the range 3.01-3.2 B.M are consistent with the above moiety ${ }^{36-37}$.

Table 2. Spectral features and magnetic moment of MIPQ ligand and it's heterochelates

\begin{tabular}{|c|c|c|c|c|c|}
\hline Heterohelates & $\begin{array}{c}\mu_{\text {eff }} \\
(\mathrm{BM})\end{array}$ & $\begin{array}{c}\text { Electronic spectral } \\
\text { data }, \mathrm{cm}^{-1}\end{array}$ & Transition & \multicolumn{2}{|c|}{$\begin{array}{l}\text { IR spectral features } \\
\text { common for all, } \mathrm{cm}^{-1}\end{array}$} \\
\hline (MIPQ)-Cu ${ }^{2+}$ & 2.09 & $\begin{array}{l}23164 \\
15776\end{array}$ & $\begin{array}{l}\text { Charge transfer } \\
{ }^{2} \mathrm{~B}_{1 \mathrm{~g}} \rightarrow{ }^{2} \mathrm{~A}_{1 \mathrm{~g}}\end{array}$ & $\begin{array}{l}1630 \\
1575 \\
1500\end{array}$ & $\begin{array}{l}\text { Quinoline } \\
\text { moiety }\end{array}$ \\
\hline (MIPQ)-Ni ${ }^{2+}$ & 3.15 & $\begin{array}{l}22525 \\
15355\end{array}$ & $\begin{array}{l}{ }^{3} \mathrm{~A}_{1 \mathrm{~g}} \rightarrow{ }^{3} \mathrm{~T}_{1 \mathrm{~g}}(\mathrm{P}) \\
{ }^{3} \mathrm{~A}_{1 \mathrm{~g}} \rightarrow{ }^{3} \mathrm{~T}_{1 \mathrm{~g}}(\mathrm{~F})\end{array}$ & $\begin{array}{l}2980 \\
2850 \\
1470\end{array}$ & $\mathrm{CH}_{2}$ \\
\hline$(\mathrm{MIPQ})-\mathrm{Co}^{2+}$ & 4.41 & $\begin{array}{c}22635 \\
15223 \\
8889\end{array}$ & $\begin{array}{c}{ }^{4} \mathrm{~T}_{1 \mathrm{~g}}(\mathrm{~F}) \rightarrow{ }^{4} \mathrm{~T}_{2 \mathrm{~g}}(\mathrm{~F}) \\
{ }^{4} \mathrm{~T}_{1 \mathrm{~g}}(\mathrm{~F}) \rightarrow{ }^{4} \mathrm{~T}_{2 \mathrm{~g}} \\
{ }^{4} \mathrm{~T}_{1 \mathrm{~g}}(\mathrm{~F}) \rightarrow{ }^{4} \mathrm{~T}_{2 \mathrm{~g}}(\mathrm{P})\end{array}$ & $\begin{array}{c}1100 \\
435\end{array}$ & $\begin{array}{c}\text { C-O-M \& } \\
\text { O-M } \\
\text { bands }\end{array}$ \\
\hline (MIPQ)-Mn ${ }^{2+}$ & 5.32 & $\begin{array}{l}23775 \\
18330 \\
16735\end{array}$ & $\begin{array}{l}{ }^{6} \mathrm{~A}_{1 \mathrm{~g}} \rightarrow{ }^{6} \mathrm{~A}_{2 \mathrm{~g}} \mathrm{C}_{\mathrm{g}} \\
{ }^{6} \mathrm{~A}_{1 \mathrm{~g}} \rightarrow{ }^{4} \mathrm{~T}_{2 \mathrm{~g}}(4 \mathrm{G}) \\
{ }^{6} \mathrm{~A}_{1 \mathrm{~g}} \rightarrow{ }^{4} \mathrm{~T}_{1 \mathrm{~g}}(\mathrm{PG})\end{array}$ & $\begin{array}{l}710 \\
750\end{array}$ & $\mathrm{Ar}-\mathrm{Cl}$ \\
\hline (MIPQ)- $\mathrm{Zn}^{2+}$ & Diamag. & - & -18 & - & - \\
\hline
\end{tabular}

\section{Antimicrobial screening}

To assess the biological potential of the ligands and their macrocyclic complexes, laboratory experiments have been conducted. The following techniques have been used for the antimicrobial activities of these compounds.

In this technique sterilized hot nutrient agar medium and $5 \mathrm{~mm}$ diameter paper discs of Whatman were used. The agar medium was poured into the petri plates. After solidifications, the petri plates were stored in inverted position so that there was condensation of water in the upper lid. Solutions of test compounds in DMSO in 500 and 1000 ppm concentrations were prepared in which discs were dipped in solution of the test sample placed on seeded plates. The petri plates having these discs on the seeded agar should first be placed at low temperature for two or four hours to allow for the diffusion of chemicals before being incubated at suitable optimum temperature $28 \pm 2{ }^{\circ} \mathrm{C}$ for $24-30 \mathrm{~h}$. After the expiry of their incubation period, 
the zone of inhibition associated with the treated disc was measured in $\mathrm{mm}$. The compounds were tested against Pseudomonas aeruginosa, Escherichia coli gram positive and Serratia marcescens, Bacillus substilis gram negative organism.

The examination of antimicrobial activity of 1-(H)-secnidazole ligand and its all heterochelates (Table 3) reveals that the ligand is moderately more or less active against various organisms, while all the heterochelates are more active than ligand. Among all the heterochelates the $\mathrm{Cu}^{2+}$ chelate is more active against organisms used.

Table 3. Antimicrobial activity of MIPQ lidand and its heterochelates

\begin{tabular}{ccccc}
\hline Compound & $\begin{array}{c}\text { Pseudomonas } \\
\text { aeruginosa }\end{array}$ & $\begin{array}{c}\text { Escherichia } \\
\text { coli }\end{array}$ & $\begin{array}{c}\text { Serratia } \\
\text { marcescens }\end{array}$ & $\begin{array}{c}\text { Bacillus } \\
\text { substilis }\end{array}$ \\
\hline Ligand & 12 & 17 & 15 & 18 \\
$(\mathrm{MIPQ})-\mathrm{Cu}^{2+}$ & 28 & 25 & 31 & 28 \\
$(\mathrm{MIPQ})-\mathrm{Ni}^{2+}$ & 21 & 18 & 29 & 26 \\
$(\mathrm{MIPQ})-\mathrm{Co}^{2+}$ & 25 & 22 & 22 & 26 \\
$(\mathrm{MIPQ})-\mathrm{Mn}^{2+}$ & 19 & 20 & 27 & 17 \\
$(\mathrm{MIPQ})-\mathrm{Zn}^{2+}$ & 24 & 23 & 24 & 19 \\
\hline
\end{tabular}

\section{References}

1. Iqbal S A and George Jacob, Orient J Chem., 2007, 23(3), 1123-1126.

2. Priya Budhani, Iqbal S. A and Suman Malik, Orient J Chem., 2005, 21(1), 147-150.

3. Farhana Afridi, Iqbal S. A and Rashida Qureshi, Orient J Chem., 2004, 20(4), 677-680.

4. Mamta Bhattacharya, Iqbal S A and Suman Malik, Orient J Chem., 2004, 20(4), 643-646.

5. Farhana Afridi, Iqbal S. A and George Jacob, Orient J Chem., 2004, 20(2), 413-414.

6. Iqbal S. A, Sadaf Farooqui and Suman Malik, Orient J Chem., 2003, 19(1), 242.

7. Rashida Qureshi and Iqbal S. A, Orient J Chem., 1998, 14(3), 481-482.

8. George Jacob and Iqbal S. A, Orient J Chem., 1998, 14(2), 336.

9. Iqbal S. A, George Jacob and Suman Malik, Orient J Chem., 1998, 14(1), 116.

10. Iqbal S. A and George Jacob, Orient J Chem., 1996, 12(2), 148.

11. George Jacob and Iqbal S. A, Orient J Chem., 1995, 11(3), 249.

12. Iqbal S.A and Asmi Desnavi, Orient J Chem., 1989, 5(2), 194-195.

13. Asmi Desnavi and Iqbal S.A., Orient J Chem., 1988, 4(1), 62-64.

14. Rashida Qureshi and Iqbal S.A, Orient J Chem., 1987, 3(1), 96-98.

15. Raikhshtat M M, Savvin S.B and Gribov L.A, Zh Anal Khim., 1979, 34, 1886.

16. Gribov L A, Savvin S.B and Raikhshtat M.M, Zh Anal Khim., 1980, 35, 1469.

17. Gonzalez-Vera J A, Lukovic E and Imperiali B, J Org Chem., 2009, 74(19), 7309.

18. Barkhater J H and Teib R I, J Org Chem., 1968, 26, 4078.

19. Abraham W, Rani K and Abrahaks P, U.S Patent, 1976, 4317887.

20. Katshutoshi L and Hideki L, Japan Patent, 1998, 1017953.

21. Portanna T.D, Anana, B.P and Rajvin Z.A, Visakamol Soedin., 1975, 17, 120.

22. Kenichiro A, Zaaea T and Sakurasaaea T, Seni Gakkaiski., 2001, 57, 229.

23. Dunya A.D, Sukhina S.J, Sinyavskii V.G and Kabrak Y.P, Ukr Khim Zh., 1982, 48, 1087.

24. Xiamren C, Yushi F, Hisann L, Kazuhisa H and Kusabbura A, Anal Sci., 1955, 11, 313.

25. Abraham A.W, Abraham D and Rami K S, African Patent, 1976, 7704289.

26. Den J, Appl Poly Sci., 1979, 2414425.

27. Patel D K and Singh A, E - J Chem., 2009, 6(4), 1017.

28. Patel H S and Oza K K, E-J Chem., 2009, 6(2), 371. 
29. Voge A I, Textbook of Quantitative Chemical Analysis, ELBS $4^{\text {th }}$ Edn., London, 1978.

30. Murrey P R, Boron E J, Pfuller M A, Tenovor F C and Yolken R H, American Society for Microbiology, Washington DC, 1995, 1327.

31. Arthinton B A, Motley. M D W Warnoek and Morrison C J, J Clin Microbilogy, 2000, 38, 1254.

32. Pancholi H.B and Patel M.M, J Polym Mater., 1996, 13, 261-267.

33. Papplardo R, J Chem Phy., 1960, 33, 613.

34. Lewis J and Wilkins R S, Modern Coordination Chemistry, New York, 1960, 290.

35. Furlani C and Morpurgo G, Theoret Chim Acta, 1965, 1, 1181.

36. Jorgenson C. K., Acta Chem Scand, 1995, 9, 1362.

37. Reddy V, Patil B R and Patil B R, J Indian Council Chem., 2006, 23(2), 1. 


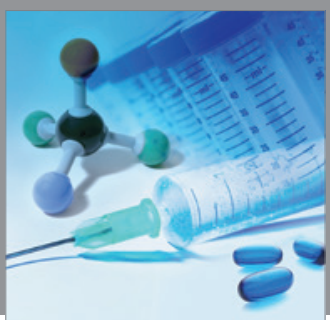

International Journal of

Medicinal Chemistry

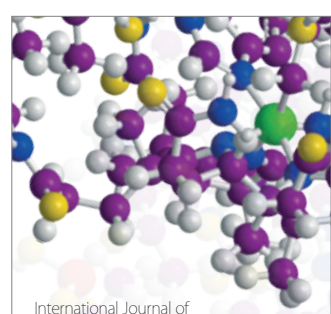

Carbohydrate Chemistry

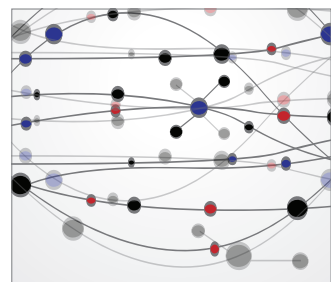

The Scientific World Journal
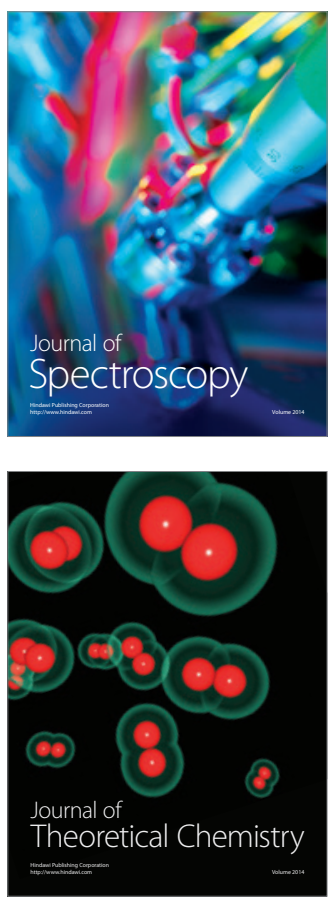
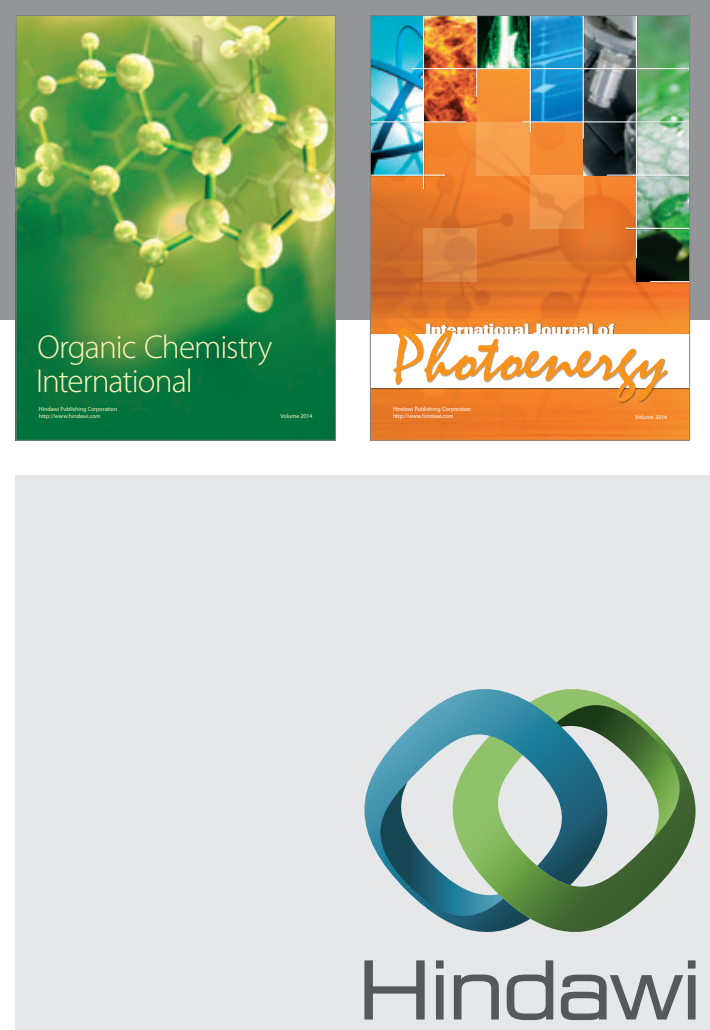

Submit your manuscripts at

http://www.hindawi.com
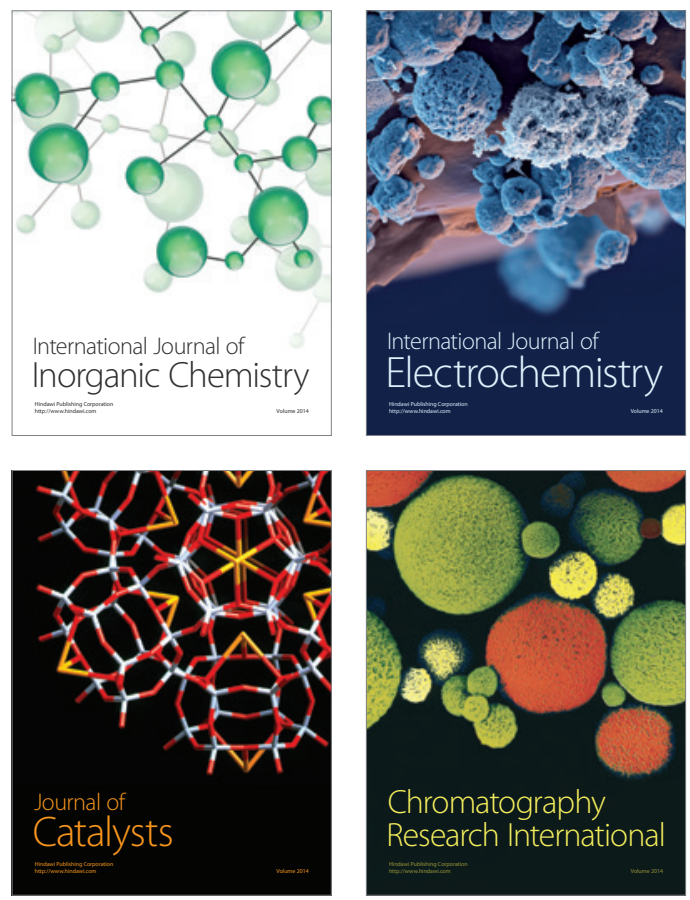
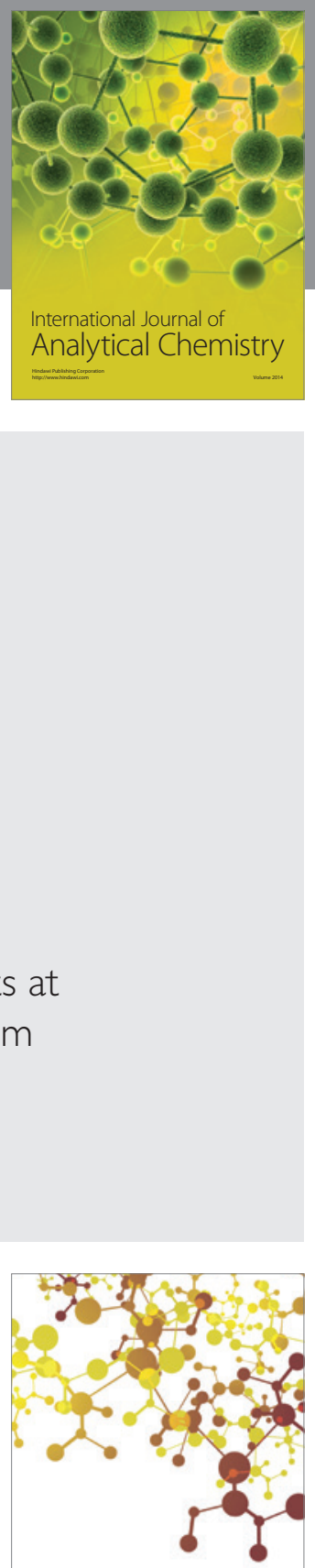

Journal of

Applied Chemistry
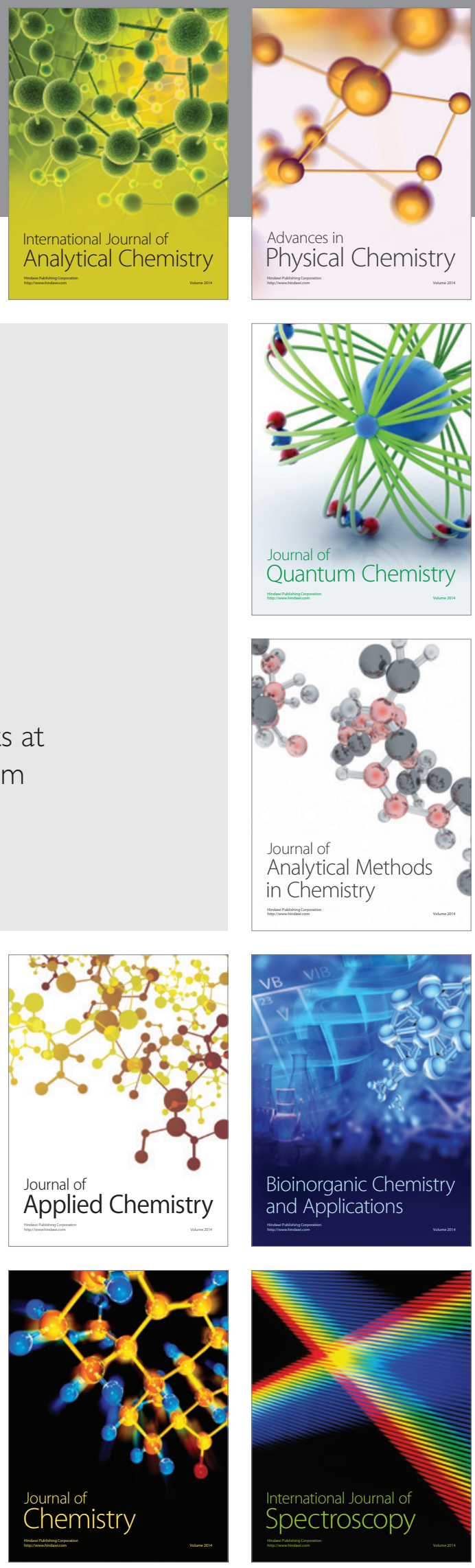